NBER WORKING PAPER SERIES

\title{
THE ROLE OF COLLATERALIZED HOUSEHOLD DEBT IN MACROECONOMIC STABILIZATION
}

\author{
Jeffrey R. Campbell \\ Zvi Hercowitz \\ Working Paper 11330 \\ http://www.nber.org/papers/w11330
NATIONAL BUREAU OF ECONOMIC RESEARCH
1050 Massachusetts Avenue
Cambridge, MA 02138
May 2005

Gadi Barlevy and Richard Suen provided insightful comments on earlier drafts of this paper. We are grateful to the National Science Foundation for research support through Grant 0137048 to the NBER. The views expressed herein are those of the author(s) and do not necessarily reflect the views of the Federal Reserve Bank of Chicago, the Federal Reserve System, or the National Bureau of Economic Research.

(O2005 by Jeffrey R. Campbell and Zvi Hercowitz. All rights reserved. Short sections of text, not to exceed two paragraphs, may be quoted without explicit permission provided that full credit, including $\odot$ notice, is given to the source. 
The Role of Collateralized Household Debt in Macroeconomic Stabilization Jeffrey R. Campbell and Zvi Hercowitz

NBER Working Paper No. 11330

May 2005

JEL No. E3

\begin{abstract}
Market innovations following the financial reforms of the early 1980s relaxed collateral constraints on household borrowing. The present paper examines the contribution of this development to the macroeconomic stabilization that occurred shortly thereafter. The model combines collateral constraints on households with heterogeneity of thrift in a calibrated general equilibrium setup. We use this tool to characterize the business cycle implications of lowering required down payments and rates of amortization for durable goods purchases as in the early 1980s. The model predicts that this relaxation of collateral constraints can explain a large fraction of the actual volatility decline in hours worked, output, household debt, and household durable goods purchases.

Jeffrey R. Campbell

Economic Research

Federal Reserve Bank of Chicago

Chicago, IL 60615

and NBER

jcampbell@frbchi.org

Zvi Hercowitz

Eitan Berglas School of Economics

Tel Aviv University

Tel Aviv, Israel

69978

zvih@post.tau.ac.il
\end{abstract}




\section{Introduction}

This paper examines the implications of the financial reforms in the early 1980's for macroeconomic volatility. The market innovations that followed the Monetary Control Act of 1980 and the Garn-St. Germain Act of 1982 relaxed collateral constraints on household debt. The well-known decline in macroeconomic volatility occurred a short time after these reforms. Because this stabilization was particularly dramatic for residential investment, Stock and Watson $(2002$, 2003) suggest these reforms as one of its sources. An examination of the behavior of household debt, reported below, supports such a link. Debt starts to accelerate at about the same time that macroeconomic volatility drops, and its standard deviation goes down more than most key aggregates'. Additionally, debt is strongly correlated with hours worked until the early 1980's, and much less so afterwards. Microeconomic evidence also indicates a connection between labor supply and household debt. Using Canadian and Italian data, Fortin (1995) and Del Boca and Lusardi (2003) found that the labor supply of married women increases with their households' mortgage debts. Taken together, this evidence motivates us to explore the connection between collateralized household debt, labor supply, and macroeconomic volatility using a quantitative general equilibrium model.

The model combines trade between a patient saver and an impatient borrower with realistic features of most household loan contracts in the U.S.- a required down payment and rapid amortization. In equilibrium, the borrower has no financial assets. When expanding purchases of home capital goods, the borrower must increase labor supply to finance down payments. The higher labor supply persists because of debt repayment. Relaxing the collateral constraints - by reducing the down-payment rate or extending the term of the loans - weakens the link between durable purchases, debt, and hours worked; and thereby results in lower aggregate variability.

This paper follows Krusell and Smith (1998) in considering the cyclical implications of heterogeneity in thrift interacting with a borrowing constraint-which in their framework is a fixed zero-debt limit. In their economy's equilibrium, the limit practically disconnects a large fraction of agents from the capital market. Krusell and Smith did not introduce endogenous labor in this economy. We conjecture that such a modification would not change aggregate behavior significantly since, with standard preferences, a constrained household keeps hours worked constant. ${ }^{1}$ In contrast, the collateral requirement in our framework amplifies constrained households' labor fluctuations by linking hours worked with durable goods purchases.

\footnotetext{
${ }^{1}$ We return to this point in Footnote 11.
} 
In the present paper, home capital plays a dual role for households, as collateral for loans and as an intrinsically valued good, just as market capital plays a dual role for firms in Kiyotaki and Moore (1997). Endogenous transmission mechanisms arise in both setups. In Kiyotaki and Moore, an exogenous shock that increases net worth of a credit-constrained firm raises its investment. Iacoviello (2004) develops a model where this type of mechanism also amplifies credit-constrained households' demand for goods. In the present framework, the transmission mechanism works through labor supply of credit-constrained households.

We stress the role of collateral constraints by first using standard preferences and production possibilities, subject to exogenous productivity shocks. With this specification, output volatility depends primarily on the variance of the productivity shocks - as in the basic RBC model-because inputs vary relatively little. Hence, relaxation of the collateral constraints reduces output's volatility modestly in spite of a substantial stabilization of hours worked. Following King and Rebelo (2000), we then introduce preferences and production possibilities that reduce the size of the exogenous shocks consistent with a given volatility of output. This version of the model predicts that relaxing collateral constraints does substantially reduce macroeconomic volatility.

Models with home production also address the cyclical interaction of home capital with hours worked. In those models, comovement depends on the technological role assigned to home capital. Rupert, Rogerson, and Wright (2000) point out that home production by itself should not generate a link between home capital and labor supply under perfect capital markets. Fisher (2001) incorporates a mechanism by which home capital improves the effectiveness of hours worked in the market. This setup generates a positive comovement between home capital and labor supply by technological means. In our framework, the interaction arises from financial factors.

The remainder of this paper proceeds as follows. In the next section, we discuss the history of household loan markets and their reforms. In Section 3 we present evidence on the cyclical behavior of household debt and its association with the decline of macroeconomic volatility. Section 4 presents the borrower-saver model, and in Section 5 the model's steady state is used to analyze long-run responses to financial market reforms. Section 6 builds intuition by analyzing the borrower's labor supply decisions in partial equilibrium. The quantitative results from calibrated versions of the model are reported in Section 7, and Section 8 concludes. 


\section{A Short History of Household Credit Markets}

We present here a brief history of household credit markets to provide a context for our analysis. In this section and in the rest of the paper we abstract from unsecured debt. According to the Survey of Consumer Finances, homes and vehicles collateralized 85 percent of total U.S. household debt in 1962 and almost 90 percent in $2001 .^{2}$

Prior to the Great Depression, typical mortgage payments were only interest, and homeowners refinanced their loans' principles every few years. Semer et. al. (1986) report that first mortgages had low loan-to-value ratios, but second and third mortgages with higher interest rates were common. For other household durable goods, a multitude of finance companies provided installment credit through retailers. (Olney (1991)).

The Great Depression and its aftermath affected these two segments of the household lending market quite differently. Federal involvement in the mortgage market became massive, while other household credit was regulated much less. Deflation during the depression period eroded housing values without affecting nominal balances due at maturity, so many borrowers were unable to find lenders to refinance their loans. The resulting defaults motivated the Hoover and Roosevelt administrations to exercise greater federal control over mortgage lending.

The Federal Home Loan Bank Act of 1932 and the Home Owners' Loan Act of 1933 established a new environment for mortgage lending based on three regulatory principles. First, regulation constrained savings and loans to raise most of their funds with short-term deposits. Congress intended this to insulate the mortgage market from fluctuations in other capital markets. Second, the federal government became savings and loans' lender of last resort. Finally, long-term amortized mortgages replaced the previous interest-only, periodically refinanced mortgages. This reduced the possibility of systemic default risk at the cost of raising borrowers' required equity in their homes.

Federal intervention in the mortgage market increased during the Korean War. In October

\footnotetext{
${ }^{2}$ From the Survey of Financial Characteristics of Consumers, conducted in 1963, Projector and Weiss (1966), Table 14, report that homes and real estate secured 77 percent of household debt, and automobiles another 8 percent. Using data from the 2002 Survey of Consumer Finances, Aizcorbe, Kennickell, and Moore (2003) report that borrowing collateralized by residential property accounted for 81.5 percent of households' debt in 2001 (Table 10), and installment loans, which include both collateralized vehicle loans and unbacked education and other loans, amounts to an additional 12.3 percent. Credit card balances and other forms of debt account for the remainder. The reported uses of borrowed funds (Table 12) indicate that vehicle debt represents 7.8 percent of total household debt, and, hence, collateralized debt (by homes and vehicles) represents almost 90 percent of total household debt in 2001.
} 
1950, the Federal Reserve imposed tight limits on the maximum amounts borrowed and minimum amortization rates (Regulation X) in order to reduce private demand. The Federal Reserve suspended these limits in September 1952. ${ }^{3}$

The maturity imbalance between Savings and Loans' long-term assets and short-term liabilities posed no challenge in a stable monetary environment, but the volatile financial markets of the late 1960s and 1970s pushed many savings and loans into insolvency. By 1980, the Volker monetary policy made the Savings and Loans' regulatory environment unsustainable. The federal government abandoned the New Deal regulatory system with the Monetary Control Act of 1980 and the Garn-St.Germain Act of 1982. This legislation eliminated restrictions on mortgage lending and reintegrated it with other financial markets. ${ }^{4}$

Figure 1 illustrates the implications of credit market regulation since 1954. It plots the ratio of mortgage debt to the value of owner-occupied housing, and the ratio of total household debt to total tangible assets - owner-occupied housing and durable goods. ${ }^{5}$ The rapid increase in the early part of the sample reflects the relaxation of residential credit controls near the end of the Korean War. This trend partially reverses in 1966 with the extension of interest rate ceilings on demand deposits (Regulation Q) to Savings and Loans. The ratio declined through the financial volatility of the late 1960s and 1970s. At the end of 1982 the debtasset ratios start a new dramatic increase. This surge reflects the emergence of the subprime mortgage lending market and households' greater use of home equity loans and mortgage refinancing to cash-out previously accumulated equity. Greater access to refinancing and home equity loans allowed homeowners to delay repayment of mortgage principle, and access to additional subprime mortgages reduced effective down payment requirements. After 1995, the ratios of household debt to tangible assets stabilize at new and higher levels.

Although only the mortgage market underwent dramatic regulatory changes, the automobile loan market also changed substantially. For the 1920s, Olney (1991) reports typical terms of car loans of $1 / 3$ down and a repayment period of 12-18 months. During the 19721982 period, the average figures are 13 percent down and repayment period of 40 months, while in the 1995-2003 period, the corresponding averages are 8 percent down and repayment

\footnotetext{
${ }^{3}$ The suspension of Regulation X, before the war ended in July 1953, was due to a provision in the authorizing statute that the restrictions would be interrupted if residential construction starts fell below a pre-specified level.

${ }^{4}$ For a detailed chronology of events leading to financial market deregulation, see Florida (1986), and the articles contained therein.

${ }^{5}$ The source of these observations is the Federal Reserve Flow of Funds Accounts, Table B.100, Balance Sheet of Households and Nonprofit Organizations.
} 
period of 54 months. ${ }^{6}$ Hence, collateral requirements in this market eased considerably over time. $^{7}$

\section{The Cyclical Behavior of Household Debt}

The financial developments at the end of 1982 preceded a fast increase in household debt and a dramatic change in its cyclical behavior. Figure 2 shows the fluctuations of total real household debt and its comovement with hours worked. Real debt equals nominal household debt deflated by the GDP price index, and hours worked is an index of total private weekly hours. Both variables are logged and HP-filtered. The Figure shows two remarkable phenomena. First, debt's volatility declines dramatically in the early 1980s. Second, debt and hours worked comove strongly until this time. Afterwards, their movements become much less synchronized.

Tables 1 and 2 summarize these data. Three periods are considered: (1) From the beginning of the sample in 1954:I through 1982:IV - the quarter of the Garn-St. Germain Act's passage - (2) from 1983:I onwards, and (3) from 1995:I onwards.

Table 1 reports the standard deviations of total household debt and mortgage debt along with those of other key macroeconomic variables in these three periods. The standard deviation of total debt declines from 2.8 percent in the period through 1982:IV, to 0.6 percent from 1995:I onwards. The corresponding figures for mortgage debt are 2.3 percent and 0.9 percent. Table 1 also illustrates the decline in general macroeconomic volatility. The standard deviations of hours worked, durable consumption expenditures, nondurable consumption expenditures, and GDP all fall substantially after 1982; and they are even lower from 1995 onwards. As stressed by Stock and Watson (2002, 2003), the decline in investment volatility reflects primarily residential investment: Its standard deviation falls from 12 percent to 2.7 percent, while the standard deviation of nonresidential investment drops from 5.1 percent to 4.5 percent. Column (4) reports the ratios of the standard deviations in the last period to those in the first. By this measure, household debt and residential investment stabilize the most.

Table 2 quantifies the comovement of hours worked and debt. Prior to 1983, the correlation coefficients of total and mortgage debt with hours worked are 0.86 and 0.83 , respectively. These correlations are substantially lower in the post-1982 sample, and they are nearly zero

\footnotetext{
${ }^{6}$ The source of these observations is Federal Reserve Statistical Release G-19, Consumer Credit.

${ }^{7}$ We consider below in Footnote 21 the implications of assuming that the changes in repayment periods reflect increased durability of automobiles.
} 
from 1995 onwards. Thus, the strong positive link between hours worked and debt seems to have broken down sometime after 1982.

One may wonder whether the levels of hours worked and household debt also changed. Figure 3 plots the log-levels of per capita real household debt and hours worked. ${ }^{8}$ Both series display a clear breaking point in 1983:I, when the debt accelerates - consistently with the increase in the ratio of household debt to tangible assets from Figure 1-and hours worked per capita begins a persistent increase. ${ }^{9}$

The evidence presented in this section indicates that the financial reforms of the early 1980s coincided with substantial macroeconomic changes. First, aggregate volatility declined. In particular, the standard deviations of household debt, residential investment, and durable purchases dropped dramatically. Second, the strong positive comovement between hours worked and debt disappeared. Third, the levels of household debt and hours worked increased. The remainder of this paper explores the possibility that these changes arose endogenously following the exogenous relaxation of collateral constraints on household borrowing. ${ }^{10}$

\section{The Borrower-Saver Model}

The model combines heterogeneity of time preference with collateral constraints. Household debt reflects intertemporal trade between an impatient borrower and a patient saver. We denote their rates of time preference with $\rho$ and $\varrho$, where $\rho>\varrho$. Durable goods collateralize all household debt.

Without collateral constraints, the borrower's debt to the saver increases over time to the maximum level the borrower can service using total labor income. Imposing collateral constraints limits the debt, so the economy possesses a unique steady state with positive

\footnotetext{
${ }^{8}$ Both variables were constructed using the civilian noninstitutional population, 16 years and older.

${ }^{9}$ Mortgage debt displays similar behavior.

${ }^{10}$ Of course, other factors could account for these changes. For discussions of alternative explanations, see McConnell and Perez-Quiros (2000), Blanchard and Simon (2001), Kahn, McConnell, and Perez-Quiros (2002), Stock and Watson (2002, 2003), and Campbell and Fisher (2004). Among these, one explanation related to ours holds that financial liberalization may affect macroeconomic volatility by increasing households' ability to smooth consumption. However, as Blanchard and Simon (2001) point out, this channel does not seem a promising route for explaining the greater macroeconomic stability since the early 1980s. The volatility of nondurable consumption and services should decline, but the volatility of durable purchases should increase - due to easier adjustment towards optimal stocks. In contrast, the actual volatility of all three components of consumption declined substantially since the early 1980s.
} 
consumption by both households. In general, the collateral constraint may bind only occasionally. However, it always binds if the economy remains close to its steady state; so standard log-linearization techniques can characterize its equilibrium for small disturbances. This is the solution approach we follow below.

The remainder of this section presents the economy's primitives, discusses the households' optimization problems, and defines a competitive equilibrium.

\subsection{Preferences}

The following utility functions represent the borrower's and saver's preferences:

$$
\begin{aligned}
& E\left[\sum_{t=0}^{\infty} e^{-\rho t}\left(\theta \ln \hat{S}_{t}+(1-\theta) \ln \hat{C}_{t}+\varphi \ln \left(1-\hat{N}_{t}\right)\right)\right], \quad 0<\theta<1, \varphi>0, \\
& E\left[\sum_{t=0}^{\infty} e^{-\varrho t}\left(\theta \ln \tilde{S}_{t}+(1-\theta) \ln \tilde{C}_{t}\right)\right] .
\end{aligned}
$$

In (1), $\hat{S}_{t}$ and $\hat{C}_{t}$ denote the borrower's consumption of durable and nondurable goods; and $\hat{N}_{t}$ is the borrower's labor supply. Similarly, $\tilde{S}_{t}$ and $\tilde{C}_{t}$ are the saver's consumption of these goods in (2).

The saver's preferences differ from those of a borrower in two respects: The rate of time preference is strictly smaller and they do not involve labor supply. The latter approximates a situation where the saver's accumulated wealth is large enough so that the corresponding labor supply decision is quantitatively unimportant.

\subsection{Technology}

The aggregate production function is

$$
Y_{t}=K^{\alpha}\left(A_{t} N_{t}\right)^{1-\alpha}, \quad 0<\alpha<1
$$

Here, $Y_{t}$ is output, $K$ is a constant capital stock, $N_{t}$ is labor input, and $A_{t}$ is an exogenous productivity index. The assumption that $K$ is constant simplifies the analysis in an aspect that is marginal in the present context - which focuses on household capital goods. Furthermore, capital stock movements are slow and thus not important for output volatility. We discuss the implications of relaxing this assumption below in Section 7.5. 
Output can be costlessly transformed into nondurable consumption and durable goods purchases. That is,

$$
Y_{t}=C_{t}+S_{t+1}-(1-\delta) S_{t}
$$

where $C_{t}$ and $S_{t}$ are the aggregate nondurable consumption and durable goods stock at time $t$. The durable good depreciates at the rate $\delta$.

The productivity shock follows the $\mathrm{AR}(1)$ stochastic process

$$
\ln A_{t}=\eta \ln A_{t-1}+u_{t}, \quad 0 \leq \eta<1,
$$

where $u_{t}$ is an i.i.d. disturbance with zero mean and constant variance. We abstract from growth in this paper.

\subsection{Trade}

A large number of firms rent the fixed capital stock from households, purchase the borrower's labor services, and sell output in perfectly competitive markets. The rental rate of capital and the wage rate are denoted by $H_{t}$ and $W_{t}$.

The collateralizable value of the durable goods stock is generally less than its replacement cost. For the stock $S_{t+1}$, it is given by

$$
V_{t+1}=(1-\pi) \sum_{j=0}^{\infty}(1-\phi)^{j}\left(S_{t-j+1}-(1-\delta) S_{t-j}\right) .
$$

Here, $\pi$ is the fraction of a new durable good that cannot serve as collateral, and $\phi$ is the rate at which a good's collateral value depreciates. We assume that $\phi \geq \delta$, so that the good's value to a creditor declines at least as rapidly as its value to its owner. Collateral limits household borrowing. That is,

$$
\hat{B}_{t+1} \leq \hat{V}_{t+1}, \quad \tilde{B}_{t+1} \leq \tilde{V}_{t+1}
$$

where $\hat{B}_{t+1}$ and $\tilde{B}_{t+1}$ are the outstanding debts of the two households at the end of period $t$, and $\hat{V}_{t+1}$ and $\tilde{V}_{t+1}$ are the collateral values of their durable goods stocks. The gross (real) interest rate on $B_{t+1}$ is $R_{t+1}$, which is determined at time $t$.

When collateral limits a household's borrowing, $\pi$ is the required down-payment rate for durable goods purchases and $\phi$ is the rate at which the principal is repaid. We treat these two parameters as exogenously determined by the regulatory environment. 
To complete the model's market structure, we assume that unbacked state-contingent claims are unenforceable. Hence, the only security traded is one-period collateralized debt. In this environment, the two households choose asset holdings, consumption of the two goods, and (for the borrower) labor supply to maximize utility subject to the budget and the borrowing constraints. Firms choose their outputs and inputs to maximize their profits. We now turn to the characterization of each of these decision problems.

\subsection{Utility Maximization}

The condition that the market in collateralized debt must clear implies that the borrowing constraint binds for at most one type of household. We conjecture that near the steady state it binds for the borrower. After characterizing the steady state, verifying this is straightforward. We now turn to the analysis of the households' utility maximization problems, given this conjecture.

\subsubsection{Utility Maximization by the Borrower}

Consider first the borrower's problem given the assumption that (6) always binds for this household. This allows us to replace $\hat{V}_{t+1}$ with $\hat{B}_{t+1}$ in (5) and rewrite the borrowing constraint as

$$
\hat{B}_{t+1}=(1-\phi) \hat{B}_{t}+(1-\pi)\left(\hat{S}_{t+1}-(1-\delta) \hat{S}_{t}\right) .
$$

With a perpetually binding borrowing constraint, the borrower never purchases productive capital. Hence, the corresponding budget constraint is

$$
\hat{C}_{t}+\hat{S}_{t+1}-(1-\delta) \hat{S}_{t}=W_{t} \hat{N}_{t}+\hat{B}_{t+1}-R_{t} \hat{B}_{t}
$$

Given $\hat{B}_{0}$ and $\hat{S}_{0}$, the borrower chooses state-contingent sequences of $\hat{C}_{t}, \hat{S}_{t+1}, \hat{N}_{t}$, and $\hat{B}_{t+1}$ to maximize the utility function in (1), subject to the sequences of constraints in (7) and (8).

Denote the current-value Lagrange multiplier on (8) with $\Psi_{t}$. If we express the Lagrange multiplier on $(7)$ as $\Xi_{t} \Psi_{t}$, then $\Xi_{t}$ measures the value in units of either consumption good of marginally relaxing the borrowing constraint.

In addition to the two binding constraints and the transversality conditions,

$$
\lim _{t \rightarrow \infty} E\left[e^{-\rho t} \Psi_{t}\right]=\lim _{t \rightarrow \infty} E\left[e^{-\rho t} \Psi_{t} \Xi_{t}\right]=0,
$$

the optimality conditions for this maximization problem are 


$$
\begin{aligned}
\Psi_{t} & =\frac{1-\theta}{\hat{C}_{t}} \\
1-\Xi_{t}(1-\pi) & =e^{-\rho} E\left[\frac{\Psi_{t+1}}{\Psi_{t}}\left(\frac{\theta}{1-\theta} \frac{\hat{C}_{t+1}}{\hat{S}_{t+1}}+(1-\delta)\left(1-\Xi_{t+1}(1-\pi)\right)\right)\right] \\
W_{t} & =\frac{\varphi}{1-\theta} \frac{\hat{C}_{t}}{1-\hat{N}_{t}} \\
\Xi_{t} & =1-e^{-\rho} E\left[\frac{\Psi_{t+1}}{\Psi_{t}} R_{t+1}\right]+(1-\phi) e^{-\rho} E\left[\frac{\Psi_{t+1}}{\Psi_{t}} \Xi_{t+1}\right] .
\end{aligned}
$$

Equation (12) is the optimal labor supply condition. This equation can be used to highlight the key role of durable goods for labor supply in this economy. When all consumption is nondurable there are no collateralizable goods, so the borrower's budget constraint reduces to $\hat{C}_{t}=W_{t} \hat{N}_{t}$. Substituting this into (12) yields $N_{t}=1 /(\phi+1)$. Hours worked are constant because the income and substitution effects of any wage change offset each other exactly. ${ }^{11}$ Thus, removing collateralizable goods eliminates labor supply fluctuations. In this sense, the market for household credit fundamentally shapes this economy's aggregate dynamics.

The remaining optimality conditions can be used to elaborate on the implications of the collateral constraint for the borrower's choices. Equation (10) looks familiar, but the collateral constraint changes its interpretation. For an unconstrained household, such as the saver, it defines the value of relaxing the intertemporal budget constraint. The borrower does not have an intertemporal budget constraint, so $\Psi_{t}$ represents only the marginal value of additional current resources.

A standard condition for optimal investment in durable goods equates the purchase price of a durable good to its immediate payoff (the marginal rate of substitution between durable and nondurable goods) plus its discounted expected resale value. Equation (11) has the same interpretation if we define $1-\Xi_{t}(1-\pi)$ to be the effective relative price of the durable good - the actual price less the benefit from relaxing the borrowing constraint by purchasing one more unit.

Setting $\Xi_{t}$ and $\Xi_{t+1}$ to zero reduces (13) to the standard Euler equation. When the collateral constraint binds, $\Xi_{t}$ in (13) can be interpreted as the price of an asset which allows

\footnotetext{
11 This point is related to the remark made in the Introduction about adding a leisure choice to Krusell and Smith's economy with a no-borrowing constraint. Because borrowing-constrained agents-who should supply a large share of the economy's labor - do not vary hours worked, we conjecture that this modification would not change their economy's dynamics substantially.
} 
the holder to expand its debt by $(1-\phi)^{j}, j \geq 0$, in period $t+j$. It equals the payoff to additional current borrowing - the violation of the standard Euler equation - plus the asset's appropriately discounted expected resale value.

\subsubsection{Utility Maximization by the Saver}

The maximization problem of the saver is standard, but we describe its solution here for the sake of completeness. We impose the ownership of the entire capital stock on the saver, since the borrower never owns capital if (7) always binds. Given the constant stock, $\tilde{K}$, and the initial durable goods and bonds, $\tilde{S}_{0}$ and $-\tilde{B}_{0}$, the saver chooses state-contingent sequences of $\tilde{C}_{t}, \tilde{S}_{t+1}$, and $\tilde{B}_{t+1}$ to maximize utility subject to the sequence of budget constraints

$$
\tilde{C}_{t}+\tilde{S}_{t+1}-(1-\delta) \tilde{S}_{t}-\tilde{B}_{t+1}=H_{t} \tilde{K}-R_{t} \tilde{B}_{t}
$$

The right-hand side of (14) sums the sources of funds: Capital rental revenue, and principle and interest income on bonds. The left-hand side includes the three uses of these funds: Nondurable consumption, durable good purchases, and saving.

We denote the current-value Lagrange multiplier on (14) with $\Upsilon_{t}$. The first-order conditions for the saver's problem are

$$
\begin{aligned}
\Upsilon_{t} & =\frac{1-\theta}{\tilde{C}_{t}}, \\
1 & =e^{-\varrho} E\left[\frac{\Upsilon_{t+1}}{\Upsilon_{t}}\left(\frac{\theta}{1-\theta} \frac{\tilde{C}_{t+1}}{\tilde{S}_{t+1}}+1-\delta\right)\right], \\
1 & =e^{-\varrho} E\left[\frac{\Upsilon_{t+1}}{\Upsilon_{t}} R_{t+1}\right],
\end{aligned}
$$

and the budget constraint in (14). Equation (16) is a typical condition for optimal purchases of durable goods, and (17) is the standard Euler equation.

\subsection{Production and Equilibrium}

The representative firm takes the input prices as given. Letting $N_{t}$ denote labor input used by the firm, profit maximization implies that

$$
\begin{aligned}
W_{t} & =(1-\alpha) A_{t}^{1-\alpha}\left(\frac{K}{N_{t}}\right)^{\alpha}, \\
H_{t} & =\alpha A_{t}^{1-\alpha}\left(\frac{K}{N_{t}}\right)^{\alpha-1} .
\end{aligned}
$$


With the economic agents' maximization problems specified, we define a competitive equilibrium. Given the two households' initial stocks of durable goods, $\hat{S}_{0}$ and $\tilde{S}_{0}$, the stock of outstanding debt issued by the borrower and held by the saver, $B_{0}=\hat{B}_{0}=-\tilde{B}_{0}$, the predetermined interest rate on this debt, $R_{0}$, and the initial value of the technology shock, a competitive equilibrium is a set of state-contingent sequences for all prices and the borrower's, saver's, and representative firm's choices such that both households maximize utility subject to the constraints, the representative firm maximizes its profit, and

$$
\begin{aligned}
N_{t} & =\hat{N}_{t}, \\
K & =\tilde{K}, \\
Y_{t} & =\tilde{C}_{t}+\hat{C}_{t}+\tilde{S}_{t+1}+\hat{S}_{t+1}-(1-\delta)\left(\tilde{S}_{t}+\hat{S}_{t}\right), \\
B_{t+1} & =\hat{B}_{t+1}=-\tilde{B}_{t+1} .
\end{aligned}
$$

That is, input, product, and debt markets clear.

\section{The Deterministic Steady State}

We next characterize the economy's steady state. In light of the substantial long-run increases in the ratio of debt to durable goods and in hours worked after 1982, we focus here on the level effects of changing the parameters of the collateral constraint, $\pi$ and $\phi$.

In the steady state, the saver's Euler equation immediately determines the interest rate, $R=e^{\varrho}$. With $R$ in hand, we calculate the borrower's choices. Equation (13) implies that

$$
\Xi=\frac{1-e^{-\rho} R}{1-e^{-\rho}(1-\phi)}=\frac{1-e^{\varrho-\rho}}{1-e^{-\rho}(1-\phi)}>0 .
$$

Hence, the collateral constraint on the borrower binds at the steady state, as conjectured in Section 4.4. From (11), the borrower's ratio of durable to nondurable consumption is

$$
\frac{\hat{S}}{\hat{C}}=\frac{\theta}{1-\theta} \frac{e^{-\rho}}{(1-\Xi(1-\pi))\left(1-e^{-\rho}(1-\delta)\right)} .
$$

This ratio depends negatively on the effective relative price of durable goods, $1-\Xi(1-\pi)$. Using (20), $\hat{S} / \hat{C}$ can be expressed as function of the primitive parameters.

The collateral constraint in (7) immediately yields $B / \hat{S}$. Using this, $\hat{S} / \hat{C}$ from (21), the borrower's budget constraint (8), and the optimal labor supply condition (12), yields $\hat{C}$ as a linear function of $W$. 


$$
\hat{C}=W /\left[1+(R-1) \frac{B}{\hat{S}} \frac{\hat{S}}{\hat{C}}+\delta \frac{\hat{S}}{\hat{C}}+\frac{\varphi}{1-\theta}\right] .
$$

Given $\hat{C} / W$, the optimal labor supply condition (12) determines $\hat{N}$. Obtaining $W, H$, and the rest of the borrower's steady-state choices is then straightforward. The steady-state capital rental rate, the outstanding household debt, and the steady-state versions of (14) and (16) then determine the saver's choices of $\tilde{C}$ and $\tilde{S}$.

The steady state can be used to examine the long-run implications of changes in the collateral requirements. Lowering $\pi$ has no impact on $\Xi$, but it directly increases $\hat{S} / \hat{C}$ and $B / \hat{S}$. Hence, $\hat{C} / W$ decreases from (22), and $N$ increases according to (12). Intuitively, lowering the down-payment rate reduces the effective cost of durable goods to the borrower and thereby induces a shift from leisure to durable goods. Also, the ratio of household debt to the aggregate stock of durable goods, $B /(\hat{S}+\tilde{S})$, the model's counterpart to the ratios plotted in Figure 1, increases as the down-payment rate declines. ${ }^{12}$

Lowering the rate of debt repayment, $\phi$, has the same qualitative implications as reducing $\pi$. In this case, the decline in the effective cost of durable goods reflects an increase in $\Xi$. Thus, the changes in the model's steady state following a reduction in down-payment and repayment rates are qualitatively consistent with the long-run changes in hours worked and debt observed in the U.S. economy after 1982. In Section 7.6, we evaluate these effects quantitatively. ${ }^{13}$

\section{The Borrower's Labor Supply Decision}

To develop intuition for interpreting the quantitative results in the next section, we characterize here the borrower's response to wage changes in partial equilibrium. Assuming that $\phi=\delta$ simplifies this discussion.

If the borrower starts off with no assets and no durable goods $\left(\hat{B}_{0}=\hat{S}_{0}=0\right)$, then $\hat{B}_{t}=(1-\pi) \hat{S}_{t}$ for all $t \geq 1$. Replacing $\hat{B}_{t+1}$ and $\hat{B}_{t}$ with $(1-\pi) \hat{S}_{t+1}$ and $(1-\pi) \hat{S}_{t}$, the budget constraint becomes

\footnotetext{
${ }^{12}$ The ratio $\tilde{S} / B$ declines along with $\hat{S} / B$. The effect on $\tilde{S} / B$ can be shown using the budget constraints of the two households and $H K=\frac{\alpha}{(1-\alpha)} N W$.

${ }^{13}$ Greenwood, Seshadri and Yorukoglu (2003) offer another perspective on the long-run relationship between hours worked and household durable goods. In their model, home durable goods substitute for labor in home production. Hence, their increased adoption induces higher participation in market production.
} 


$$
\hat{C}_{t}+\pi \hat{S}_{t+1}=W_{t} \hat{N}_{t}+R_{t}\left[\pi-\frac{R_{t}-1+\delta}{R_{t}}\right] \hat{S}_{t} .
$$

In this form, the uses of the borrower's funds appear as nondurable consumption and down payments on the desired stock of durable goods, and the sources of funds are labor income and accumulated equity, $\left[(1-\delta)-R_{t}(1-\pi)\right] \hat{S}_{t}$, which can be written as the last term in (23).

The first-order conditions can be combined to yield

$$
e^{-\rho} \frac{\theta}{\hat{S}_{t+1}}=\frac{\varphi \pi}{W_{t}\left(1-\hat{N}_{t}\right)}-\varphi e^{-\rho} E\left[\frac{R_{t+1}\left(\pi-\frac{R_{t+1}-1+\delta}{R_{t+1}}\right)}{W_{t+1}\left(1-\hat{N}_{t+1}\right)}\right] .
$$

Here, the marginal utility of durable goods consumption is equated with the utility cost of working to acquire the down payment, less the expected utility next period from the leisure-equivalent of accumulated equity.

The key term in both equations is $\pi-\left(R_{t}-1+\delta\right) / R_{t}$, the difference between the downpayment rate and the conventionally defined user cost of durable goods. When the down payment is higher than the user cost, the collateral constraint forces the borrower to acquire some ownership of its durable goods stock. We focus next on two cases regarding this term.

\subsection{Full Collateral}

A benchmark case consists of setting $R_{t}$ equal to a constant, $R$, and the down-payment rate to $\pi=(R-1+\delta) / R$. Here, the down payment covers only the user cost. We call this the full collateral case, since the outstanding debt next period equals the depreciated durable goods stock.

Consider the effects of changes in $W_{t}$. Because the last terms in both (23) and (24) now equal zero, these equations and the first-order condition for $\hat{N}_{t}$ are satisfied only by an immediate and full adjustment of $\hat{C}_{t}$ and $\hat{S}_{t+1}$ to the wage change, while $\hat{N}_{t}$ remains constant. These choices correspond exactly to those of a household facing no borrowing constraints following a permanent wage change. Here, however, this result holds whether the change is permanent or transitory. Therefore, full collateral eliminates completely the effects of wage fluctuations on labor supply. 


\subsection{Partial Collateral}

When $\pi>(R-1+\delta) / R$, the borrowing constraint forces the household to accumulate equity on its durable goods. Correspondingly, only a fraction of the durable stock can serve as collateral. We label this case partial collateral.

With partial collateral, the borrower's accumulated equity is positive. Its presence in the budget constraint, Equation (23), makes the unconstrained household's response to a permanent wage change infeasible. Hence, the adjustment of $\hat{C}_{t}$ and $\hat{S}_{t+1}$ must be less than proportional to the wage. The optimal labor supply condition, Equation (12), and the decline of $\hat{C}_{t} / W_{t}$ then imply that $\hat{N}_{t}$ rises above its long-run level. This occurs for both permanent and transitory changes in wages.

From the borrower's partial equilibrium responses under full and partial collateral it follows that labor supply fluctuations arise from the required accumulation of equity on durable goods. We now proceed to evaluate this source of business cycle propagation quantitatively.

\section{Quantitative Results}

To assess the quantitative implications of this framework for macroeconomic volatility, we solve the model and simulate the impact of empirically relevant changes in household loan markets. We consider first a regime of high collateral requirements, for which the parameters $\pi$ and $\phi$ are matched to observations through 1982:IV. The effects of the financial market reforms in the early 1980s are then assessed by considering a regime of low collateral requirements, which is matched to observations from the period from 1995:I onwards. As shown in Figure 1, the latter period corresponds to a stabilization of the ratios of household debt to tangible assets after the reforms. We interpret this as convergence of credit markets to the new environment.

\subsection{Calibration}

Only the parameters $\pi$ and $\phi$ are assumed to differ across the two regimes. The available data to calibrate these parameters are the terms of mortgage loans from 1963 onwards, and of car loans from 1971 onwards.

We start with the high collateral-requirement regime. During the 1963-1982 period, the average term of first mortgages for new home purchases is 98 quarters and the average downpayment rate is 0.27 . Over the $1971-1982$ period, the average term of a new car loan is 13.4 
quarters and the average down-payment rate is $0.13 .^{14}$

The 98 quarter term of home loans implies a linear repayment rate of 0.01 per quarter. From the 13.4 quarter term for car loans, the corresponding repayment rate is 0.075 . Using the shares of mortgage debt and consumer credit during the 1954-1982 period - 0.7 and 0.3 respectively - $\phi$ is set at the weighted average of the two repayment rates, 0.03 .

Similarly, $\pi$ is a weighted average of the two down-payment rates, 0.27 and 0.13 . We construct the weights indirectly because there are no observations on the flows of loans for purchasing newly constructed homes. In a steady state, loans extended in each category should equal the principle repayment rate multiplied by the category's steady-state debt. Given the repayment rates and debt shares used to calibrate $\phi$, the implied shares of home and automobile loans in total loans extended are 0.24 and $0.76{ }^{15}$ The value of $\pi$ is set at the weighted average down-payment rate of 0.16 .

There is less information about $\pi$ and $\phi$ for the low collateral-requirement regime. The available data on the terms of home loans cover only first mortgages. Given the scarcity of refinancing and home equity loans prior to 1983, these data are representative of the collateral constraints in this market. The financial reforms in the early 1980s substantially widened these options, so that the terms of first mortgages cease to represent actual collateral constraints. Refinancing and second loans have never been prominent features of automobile finance, so the terms of new car loans continue to reflect actual collateral constraints. During the 1995:I-2004:II period, the average down-payment rate for cars fell to 0.11, and the average term of car loans increased to 18 quarters.

Given that the post-1982 credit market liberalization affected mainly the mortgage market, we assume that a decline in the effective down payment for homes of 5 percentage points - the decline for car loans - is a conservative estimate. Hence, we set $\pi=0.11$ for this regime. We assume that refinancing makes it possible to avoid home equity accumulation altogether. Hence, the mortgage repayment rate should equal residential structures' physical depreciation rate, 0.003 (see below). An 18 quarter auto loan term implies a linear repayment rate of 0.055 . The appropriately weighted average of these two repayment rates is $\phi=0.015 .^{16}$

The remaining parameters are held constant across the two regimes. The production function elasticity $\alpha$ equals 0.3 . The parameters of the exogenous productivity shock process

\footnotetext{
${ }^{14}$ Data on the terms of mortgages are from Federal Housing Finance Board's Monthly Interest Rate Survey. Federal Reserve Statistical Release G.19 reports the terms of new automobile loans.

${ }^{15}$ The weight for home loans is computed as $0.01 \times 0.7 /(0.01 \times 0.7+0.075 \times 0.3)=0.237$.

${ }^{16}$ The shares of mortgage debt and consumer debt in the 1995:I-2004:II period are 0.76 and 0.24 .
} 
are set as follows. Using the value $\eta=0.95$ from Hansen and Prescott $(2001), \sigma_{\eta}$ is calibrated so that the model's standard deviation of output matches its actual counterpart in the 1954:I1982:IV sample. The resulting value is 0.008 . The same values of $\eta$ and $\sigma_{\eta}$ are then used in the simulation of the second regime. The depreciation rate $\delta$ is 0.01 , the appropriately weighted average of 0.003 for owner occupied residences and 0.031 for cars. ${ }^{17}$

We chose $\varrho$ so that the quarterly interest rate is one percent. Because the borrower's discount rate does not influence the interest rate, its calibration is more difficult. We set $\rho=0.015$, i.e., half of a percentage point higher than the interest rate. This degree of impatience is similar in magnitude to that used by Krusell and Smith (1998). Using a model with 3 levels of time preference, they calibrate the differences between each type as $0.36 \%$; or $0.72 \%$ between the two extremes. We have experimented with various values for this parameter with almost identical results to those reported below.

The remaining parameters are $\theta$ and $\varphi$. We chose these simultaneously to match an average share of hours worked of 0.3 and the share of durable goods expenditure in total households' expenditures in the 1954:I-1982:IV sample of $0.21 .{ }^{18}$ Given the other parameters and the collateral requirements in this period, the unique values of $\theta$ and $\varphi$ that replicate these observations are 0.37 and 1.96. Table 3 summarizes the calibrated parameter values.

\subsection{Household Borrowing and Aggregate Dynamics}

We begin the quantitative analysis with a description of the two households' decisions in general equilibrium with the model calibrated to the high collateral-requirement regime. Figure 4 plots impulse responses of key variables to a positive productivity shock of $1 /(1-\alpha)$ percent. All the variables are expressed as percent deviations from their steady-state values. The price responses are not shown since they are similar to those in the standard Real Business Cycle model: The technology shock directly shifts up labor demand, so the wage rises and thereafter falls slowly to its steady-state level. The interest rate response has a similar shape, given the increased demand for consumption by both households, but it is very small given both households' high interest sensitivity.

\footnotetext{
${ }^{17}$ The source is "Fixed Assets and Consumer Durable Goods in the United States, 1925-97." The service life of 1-4 units residences is 80 years. Automobiles' service life of 8 years is inferred from the reported non-linear depreciation profile. We used the weights 0.75 and 0.25 , which are the shares of the owner occupied residential stock and consumer durable goods stock in the 1954-2004 sample.

${ }^{18}$ To calculate this ratio, we adjusted the NIPA's nondurable personal consumption expenditures by subtracting the imputed service flow of housing. We then added residential investment to personal consumption expenditures on durable goods.
} 
The individual households' responses illustrate the intertemporal exchange between them. Although the technology shock increases the rental income from capital, the saver's durable purchases and nondurable consumption reflect the higher interest rate: Durable consumption declines and nondurable consumption trends upwards. Hence, the saver's reaction is to purchase the borrower's debt; helping to finance a surge in the borrower's consumption. As in the partial equilibrium discussion in Section 6, the increase in hours worked by the borrower reflects partial collateral: Labor supply must increase to finance durable purchases.

A peculiar characteristic of the model is that temporarily higher income induces the borrower to increase debt - in sharp contrast with the response of a household in a standard model, or the saver in this model. This arises because the collateral constraint binds at all times. Hence, borrowing cannot be a vehicle for consumption smoothing. It is here part of the transaction of durable goods purchases.

\subsection{Collateral Requirements and Aggregate Volatility}

We turn now to the main issue in the paper: How important is the relaxation of the collateral constraints for aggregate dynamics? Figure 5 compares the impulse responses of aggregate variables under the two regimes, high and low collateral requirements, to the same $1 /(1-\alpha)$ percent increase in $A_{t}$.

In the low collateral-requirement regime, the responses of hours worked and the debt have about half the magnitude of the responses in the high-requirement regime. The response of hours worked reflects the mechanism discussed in Section 6: Moving closer to full collateral reduces the labor supply reaction to wage movements. The change in the response of the debt follows mainly from the lower repayment rate. If $\phi>\delta$, a young durable good has more collateral value than an old one with the same after-depreciation value to the owner. When a positive shock reduces temporarily the average age of the borrower's durable goods stock, its average collateral value increases accordingly. Given that the borrower fully exploits borrowing opportunities, the ratio of debt to durable goods overshoots its long-run level. This overshooting is eliminated when $\phi=\delta$, because then age is irrelevant for the collateral value of a durable good. Lowering the collateral constraint makes $\phi$ much closer to $\delta$ and greatly reduces debt overshooting.

Figure 5 also shows that the large proportional decline in the response of hours worked produces only a small decline in the response of output. Given the standard utility and production functions, the variation of hours worked is relatively small. Hence, the exogenous productivity shock dominates output dynamics. In the next subsection, we follow King 
and Rebelo (2000) and introduce preferences and production possibilities that enhance the contribution of labor fluctuations to output - and thereby reduce the exogenous variation of the shocks required to match observed output volatility.

\subsection{A High-Substitution Economy}

Here we adopt both Hansen's (1985) utility function and a production technology with intermediate inputs. The borrower's utility function is now

$$
E\left[\sum_{t=0}^{\infty} e^{-\rho t}\left(\theta \ln \hat{S}_{t}+(1-\theta) \ln \hat{C}_{t}+\gamma\left(1-\hat{N}_{t}\right)\right)\right],
$$

where $0<\theta<1$ and $\gamma>0 .{ }^{19}$ For the saver, there is no labor supply decision, so that the utility function remains the same.

The production structure is changed to increase the elasticity of output with respect to labor without altering the income shares of borrowers and savers. The production function for final goods is

$$
Y_{t}=\left(K^{\alpha}\left(A_{t} N_{t}\right)^{1-\alpha}\right)^{1-\vartheta} M_{t}^{\vartheta}, \quad 0<\alpha<1,0<\vartheta<1,
$$

where $M_{t}$ is a composite of intermediate inputs,

$$
M_{t}=\left(\int_{0}^{1} M(i)_{t}^{\rho} d i\right)^{1 / \rho} .
$$

A profit maximizing monopoly produces each input at a constant marginal cost using imported materials. Savers own all of these monopolies' shares.

If we set $\alpha=1$ and solve for the representative final goods firm's optimal level of $M_{t}$, we can express its value added as a linear function of labor input,

$$
Y_{t}=\kappa A_{t} N_{t}
$$

where $\kappa$ is a constant. ${ }^{20}$ The elasticity of output with respect to labor is now unity. However, labor's share in income is not one because the saver receives monopoly profits. These profits

\footnotetext{
${ }^{19}$ For computational purposes, we actually use $\theta \ln \hat{S}_{t}+(1-\theta) \ln \hat{C}_{t}+\gamma \frac{\left(1-\hat{N}_{t}\right)^{1-\chi}}{1-\chi}$, with a very small value for $\chi$.

${ }^{20}$ Another specification leading to a linear reduced form in labor without altering the capital share in income is $Y_{t}=\left(M_{t} K\right)^{\alpha}\left(A_{t} N_{t}\right)^{1-\alpha}$, where $M_{t}$ is here the utilization rate of capital, and the depreciation of capital is linear in $M_{t}$. This is the specification used by King and Rebelo (2000).
} 
are the difference between total payments to the monopolies and their production costs. It can be shown that savers' share of income is $\nu=\vartheta^{-\vartheta /(1-\vartheta)}-\vartheta^{1 /(1-\vartheta)}$.

Given that in this economy the capital share is $\nu$, we now calibrate this parameter, and not $\alpha$, as 0.3 . Also $\sigma_{\eta}$ is recalibrated. As with the basic economy, we chose its value so the standard deviation of output in the high collateral-requirement regime equals the standard deviation of output in the 1954:I-1982:IV period. Given the high-substitution nature of this economy, this parameter is reduced from 0.008 in the baseline economy to 0.003 . Finally, the requirement that $N=0.3$ implies that $\gamma=2.78$.

Figure 6 shows the impulse responses for the two regimes in this economy. The difference in output response between the high and low collateral-requirement regimes is more pronounced than for the baseline economy, particularly on impact.

Table 4 presents the standard deviations of HP-filtered data from both economies. The standard deviations for the baseline economy reflect the impulse response functions in Figure 5: The decline in volatility is concentrated in debt and hours.

The results are substantially different for the high-substitution economy, on which we focus henceforth. The last column of Table 4 shows that, except for nondurable consumption, volatility is substantially lower in the low collateral-requirement regime. For output, the ratio of the standard deviation in the low-requirement regime to its high-requirement counterpart is 0.66. The actual ratio from periods 1995:I-2004:II and 1954:I-1982:IV in Table 1 is 0.52. Hence, the present mechanism can reproduce a large part of the decline in output volatility. Similarly for the debt: The model's volatility ratio is 0.37 , while the actual counterpart is 0.23. The model reproduces the actual finding that the decline in the volatility of the debt is the most pronounced. The volatility decline in hours worked is overstated: The model's ratio is 0.42 , and in the data it is $0.58 .^{21}$

The model does less well in accounting for the dramatic stabilization of durable purchases. The ratio of standard deviations from the low- and high-requirement regimes is 0.54 . The actual ratios for residential investment and durable consumption purchases are 0.23 and 0.39. The model's most counterfactual result is the small decline in the volatility of

\footnotetext{
${ }^{21}$ The results are very similar when we assume that the difference in repayment rates of car loans across periods ( 0.075 per quarter prior to 1983 and 0.055 from 1995 onwards) reflects a parallel difference in cars' depreciation rates. Setting the depreciation rates of cars as 0.051 in the first regime and 0.031 in the secondthe same rate as above - the weighted average depreciation rate for the first regime is $\delta=0.017$ and for the second it remains $\delta=0.01$. Using the same values for the other parameters, except for recalibrating $\sigma_{n}$ to 0.0048 , the results remain very similar to those presented above, and in particular, the ratio of standard deviations of output is unchanged.
} 
nondurable consumption: The model's volatility ratio is 0.93 , while the actual ratio is 0.52 . The reason for these results follows from the argument presented in Section 6: Lowering collateral requirements moves consumption behavior closer to that of a permanent-income consumer. This tends to increase consumption's volatility given the high persistence of the shocks, offsetting the effects of the overall stabilization.

The decline in the correlation of hours worked with the debt, which is very large in the data, is small in the model. The correlation goes down from 0.63 to 0.59 , compared to the actual decline from 0.86 to -0.08 shown in Table 2 . The impulse responses of both variables are substantially lower in the low collateral-requirement regime, but their shapes do not change much. With only one shock in the model, this implies that their correlation changes little.

\subsection{Two Modifications of the Model}

We explore two modifications of the model in order to test the robustness of the results. One modification is to allow the capital stock to vary over time, and the other is to introduce an additional shock.

A variable capital stock implies that the saver has an additional avenue for intertemporal optimization. Given the capital share $\alpha+\nu=0.3$, we assume that $\alpha=0.1$ and $\nu=$ 0.2. The impulse responses from these economy display a well known problem with models with multiple capital stocks. Immediately following a shock there is a dramatic increase in productive investment along with a similarly strong decline in savers' purchases of durable goods. In the following period the pattern is reversed. This instability reflects the lack of adjustment costs for capital: Productive investment is built first all-at-once, and then the durable goods stock is increased. Introducing adjustment costs would alleviate this counterfactual behavior. Our assumption above that the capital stock is constant represents an extreme form of adjustment costs. The experiment of lowering the collateral requirements in this economy yields similar results as those obtained previously. The ratio of the standard deviation in the low collateral-requirement regime to its high-requirement counterpart is 0.72 , somewhat higher than the 0.65 ratio in the previous results. The difference is due to the fact that in this economy, the elasticity of output with respect to labor is lower than 1 . Hence, the change in labor volatility contributes less to reducing output's volatility.

The second modification is to introduce an income redistribution shock, assumed to be independent of the productivity shock. In the basic structure of the model, the borrower expands labor supply to finance down payments and debt repayment. The additional source 
of funds introduced here relaxes this link, and generates an opposite comovement between hours worked and debt. These funds make it possible to reduce hours and to increase down payments - and hence the debt - simultaneously. We calibrate the stochastic properties of the additional shock to the behavior of real social benefits to persons. ${ }^{22}$

With the two shocks in the model, the ratio of the standard deviation in the lowrequirement regime to its high-requirement counterpart is 0.66 , the same as with one shock. The correlation of hours worked with the debt goes down here from 0.59 to 0.45 . This decline is more pronounced than in the one-shock economy, but still far from the actual change. Under high collateral-requirements, the redistribution disturbance in isolation does generate a strong negative comovement between hours and the debt. However, moving from high to low collateral-requirements weakens this negative comovement significantly, and hence the over-all correlation declines only moderately. The results are similar if instead of redistribution we introduce a wealth shock to everyone - as with government spending financed by lump-sum taxes. In conclusion, adding disturbances working through the budget constraints does not alter the results about the stabilizing role of relaxing collateral requirements. Additionally, these disturbances contribute only partially to the explanation of the decline in the correlation of hours worked and the debt.

\subsection{Comparison of Level Changes}

Figures 1 and 3 indicate that the increase in the ratio of the debt to the durable stock following the reforms in the early 1980s coincides approximately with the trend change in hours worked per capita. The steady-state analysis in Section 5 predicts qualitatively that both hours worked and the ratio of debt to the durable stock should increase following a relaxation of the collateral constraints. Here, using the parameter values and the model's steady state, we evaluate these changes quantitatively, and compare them to the actual changes from 1954:I-1982:IV to 1995:I-2004:II.

The percentage increase in average hours per-capita across these two sample periods is 6.6 percent. In the baseline economy, the steady-state increase from the high to the low collateral-requirement regime is 5.6 percent, and in the high-substitution economy it is 8.1 percent. Hence, the model predicts the order of magnitude of the change in hours worked.

\footnotetext{
${ }^{22}$ Using HP-filtered real transfers (nominal figures divided by the GDP price index), the estimated $A R(1)$ statistics are a serial correlation of 0.73 and standard deviation of the innovation of 0.02 . The average share of these transfers in GDP during the sample is 0.08 . With the additional shock, the recalibrated $\sigma_{\eta}$ is slightly lower than the previous value 0.003 .
} 
Regarding the ratio of debt to the durable stock, the average ratio for the period 1954:I$1982: \mathrm{IV}$ is 0.34 , and for 1995:I-2004:II it is 0.41. In the two model economies, the ratios in the high and low collateral-requirements regimes are 0.18 and 0.36 . The prediction for the second period is not far from the actual ratio, but the model underpredicts it in the period with high collateral requirements.

The fact that the model generates a large increase in the ratio of household debt to assets is a fairly direct consequence of the relaxation of the collateral constraint. It is more surprising, however, that this financial change can also reproduce the observed increase in hours worked.

\section{Concluding Remarks}

This paper concentrates on the implications of collateral constraints on household debt for macroeconomic stability. The mechanism works through labor supply-lowering collateral requirements weakens the connection between constrained households' investment in durable goods and their hours worked.

The striking change in the behavior of household debt and hours worked after the financial deregulation of the early 1980s coincided with the macroeconomic volatility decline. We believe that this evidence warrants our focus on the link between household borrowing and labor supply. The quantitative results indicate that weakening this link substantially contributed to macroeconomic stability. The model also predicts the higher observed levels of hours worked and household debt.

The analysis in this paper abstracts from the implications of the financial reform for welfare. A comparison of steady states reveals nothing in this respect, because the intertemporal substitution that benefits the borrower occurs along the transition path. We expect borrowing against home equity accumulated before the reform and changes in the tax treatment of non-mortgage interest to be quantitatively significant aspects of the transition path.

We conclude by noting that the interaction of borrowers and savers in the presence of collateral constraints might have interesting implications for the analysis of monetary transmission. Lowering the interest rate in a model with standard intertemporal substitution contracts labor supply by reducing the price of current leisure relative to future leisure. In a monetary version of the present model, we expect a lower interest rate to expand labor supply by increasing the demand for durable goods. Hence, we believe that monetary economies that include collateral requirements for household borrowing merit investigation. 


\section{References}

[1] Aizcorbe, Ana M., Arthur B. Kennickell, and Kevin B. Moore, 2003, "Recent Changes in U.S. Family Finances: Evidence from the 1998 and 2001 Survey of Consumer Finances," Federal Reserve Bulletin, 89, 1-32.

[2] Blanchard, Olivier, and John Simon, 2001, "The Long and Large Decline in U.S. Output Volatility," Brookings Papers on Economic Activity, 135-164.

[3] Campbell, Jeffrey R. and Jonas D.M. Fisher, 2004, "Idiosyncratic Risk and Aggregate Employment Dynamics," Review of Economic Dynamics, 7, 331-353.

[4] Del Boca, Daniela, and Annamaria Lusardi, 2003, "Credit Market Constraints and Labor Market Decisions," Labour Economics, 10, 681-703.

[5] Fisher, Jonas D. M., 2001, "A Real Explanation for Heterogenous Investment Dynamics," Federal Reserve Bank of Chicago Working Paper \# 2001-14.

[6] Florida, Richard, L. 1986, Housing and the New Financial Markets, Rutgers-The State University of New Jersey.

[7] Fortin, Nicole, M., 1995, "Allocation Inflexibilities, Female Labor Supply, and Housing Assets Accumulation: Are Women Working to Pay the Mortgage?" Journal of Labor Economics, 13, 524-557.

[8] Greenwood, Jeremy, Ananth Seshadri, and Mehmet Yorukoglu, 2003, "Engines of Liberation," Review of Economic Studies, 72, 109-133.

[9] Hansen, Gary D, 1985, "Indivisible Labor and the Business Cycle," Journal of Monetary Economics, 16, 309-327.

[10] Hansen, Gary D., and Edward C. Prescott, 2001, "Capacity Constraints, Asymmetries, and the Business Cycle," Unpublished Manuscript.

[11] Iacoviello, Matteo, 2004, "House Prices, Borrowing Constraints and Monetary Policy in the Business Cycle," Forthcoming in the American Economic Review.

[12] Kahn, James, Margaret M. McConnell, and Gabriel Perez-Quiros, 2002, "On the Causes of the Increased Stability of the U.S. Economy," Federal Reserve Bank of New York Economic Policy Review, 8, 183-202. 
[13] King, Robert, G., Charles I. Plosser and Sergio T. Rebelo, 1988, "Production, Growth and Business Cycles I." Journal of Monetary Economics, 21, 195-232.

[14] King, Robert G., and Sergio T. Rebelo, 2000, "Resuscitating Real Business Cycles," in John Taylor and Michael Woodford (eds) Handbook of Macroeconomics, North Holland, 927-1007.

[15] Kiyotaki, Nobuhiro, and John Moore, 1997, "Credit Cycles," Journal of Political Economy, 105, 211-248.

[16] Krusell, Per, and Anthony A. Smith, Jr., 1998, "Income and Wealth Heterogeneity in the Macroeconomy," Journal of Political Economy, 106, 867-896.

[17] McConnell, Margaret. M., and Gabriel Perez-Quiros, 2000, "Output Fluctuations in the United States: What Has Changed Since the Early 1980's?" American Economic Review, 90, 1464-1476.

[18] Olney, Martha, L., 1991, Buy Now, Pay Later, The University of North Carolina Press.

[19] Projector, Dorothy S., and Gertrude S. Weiss, 1966, "Survey of Financial Characteristics of Consumers," Federal Reserve Technical Papers, August.

[20] Rupert, Peter, Richard Rogerson, and Randall Wright, 2000, "Homework in Labor Economics: Household Production and Intertemporal Substitution," Journal of Monetary Economics, 46, 557-579.

[21] Semer, Milton P., Julian H. Zimmerman, John M. Frantz and Ashley Ford, 1986, "Evolution of Federal Legislative Policy in Housing: Housing Credits," in Richard L. Florida (ed.) Housing and the New Financial Markets, Rutgers-The State University of New Jersey.

[22] Stock, James H., and Mark W. Watson, 2002, "Has the Business Cycle Changed and Why?" NBER Macroeconomics Annual, 159-218.

[23] Stock, James H., and Mark W. Watson, 2003, "Has the Business Cycle Changed? Evidence and Explanations," in Monetary Policy and Uncertainty: Adapting to a Changing Economy. Federal Reserve Bank of Kansas City. 
Table 1: Percent Standard Deviations of HP-filtered U.S. Data ${ }^{(i)}$

\begin{tabular}{|c|c|c|c|c|}
\hline & \multicolumn{4}{|c|}{ Sample Period } \\
\hline & $\begin{array}{c}\text { 1954:I-1982:IV } \\
\text { (1) }\end{array}$ & $\begin{array}{c}\text { 1983:I-2004:II } \\
(2)\end{array}$ & $\begin{array}{c}\text { 1995:I-2004:II } \\
(3)\end{array}$ & $\begin{array}{c}(3) /(1) \\
(4)\end{array}$ \\
\hline Total Debt ${ }^{(i i)}$ & 2.76 & 1.93 & 0.63 & 0.23 \\
\hline Mortgage Debt ${ }^{(i i)}$ & 2.29 & 1.81 & 0.93 & 0.41 \\
\hline Hours Worked & 1.96 & 1.49 & 1.13 & 0.58 \\
\hline Residential Investment & 12.00 & 5.33 & 2.70 & 0.23 \\
\hline Nonresidential Investment & 5.12 & 4.57 & 4.54 & 0.89 \\
\hline Durable Goods ${ }^{(i i i)}$ & 5.66 & 3.17 & 2.21 & 0.39 \\
\hline Nondurable Goods \& Services ${ }^{(\mathrm{iii}, \mathrm{iv})}$ & 1.87 & 1.10 & 1.09 & 0.58 \\
\hline Output & 1.88 & 1.11 & 0.97 & 0.52 \\
\hline
\end{tabular}

Notes: (i) All variables are logged and HP-filtered over the period 1954:I-2004:II. (ii) Nominal debt divided by the chain-weighted GDP deflator. (iii) Personal consumption expenditures on the given category. (iv) We chain subtracted housing services from personal consumption expenditures on nondurable goods and services. 
Table 2: Correlation Coefficients of HP-filtered Hours and Debt ${ }^{(i)}$

\begin{tabular}{l|ccc} 
& \multicolumn{3}{|c}{ Sample Period } \\
& 1954:I-1982:IV & 1983:I-2004:II & 1995:I-2004:II \\
\hline Total Debt \& Hours Worked & 0.86 & 0.45 & -0.08 \\
Mortgage Debt \& Hours Worked & 0.83 & 0.29 & 0.09
\end{tabular}

Note: (i) All variables are logged and HP-filtered over the period 1954:I-2004:II.

Table 3: Calibrated Parameter Values

\begin{tabular}{l|cccccccccc} 
Collateral Requirements & $\pi$ & $\phi$ & $\alpha$ & $\eta$ & $\sigma_{\eta}$ & $\delta$ & $\varrho$ & $\rho$ & $\theta$ & $\varphi$ \\
\hline High & 0.16 & 0.030 & 0.3 & 0.95 & 0.008 & 0.01 & 0.01 & 0.015 & 0.37 & 1.96 \\
Low & 0.11 & 0.015 & & & & & & &
\end{tabular}

Table 4: The Model Economy's Standard Deviations ${ }^{(i)}$

\begin{tabular}{|c|c|c|c|c|c|c|}
\hline & \multicolumn{3}{|c|}{ Baseline Economy } & \multicolumn{3}{|c|}{ High-Substitution Economy } \\
\hline & $\operatorname{High}^{(\mathrm{ii})}$ & Low $^{(i i)}$ & Ratio & $\operatorname{High}^{(i i)}$ & Low $^{(i i)}$ & Ratio \\
\hline Debt & 2.21 & 1.00 & 0.45 & 2.02 & 0.75 & 0.37 \\
\hline Hours Worked & 0.59 & 0.26 & 0.44 & 1.20 & 0.50 & 0.42 \\
\hline Nondurable Consumption & 0.81 & 0.85 & 1.06 & 0.62 & 0.58 & 0.92 \\
\hline Durable Purchases & 6.38 & 4.83 & 0.76 & 7.43 & 4.04 & 0.54 \\
\hline Output & 1.88 & 1.65 & 0.88 & 1.88 & 1.25 & 0.66 \\
\hline
\end{tabular}

Notes: (i) The entries are population standard deviations of logged and HP-filtered observations. (ii) Type of collateral requirement. 


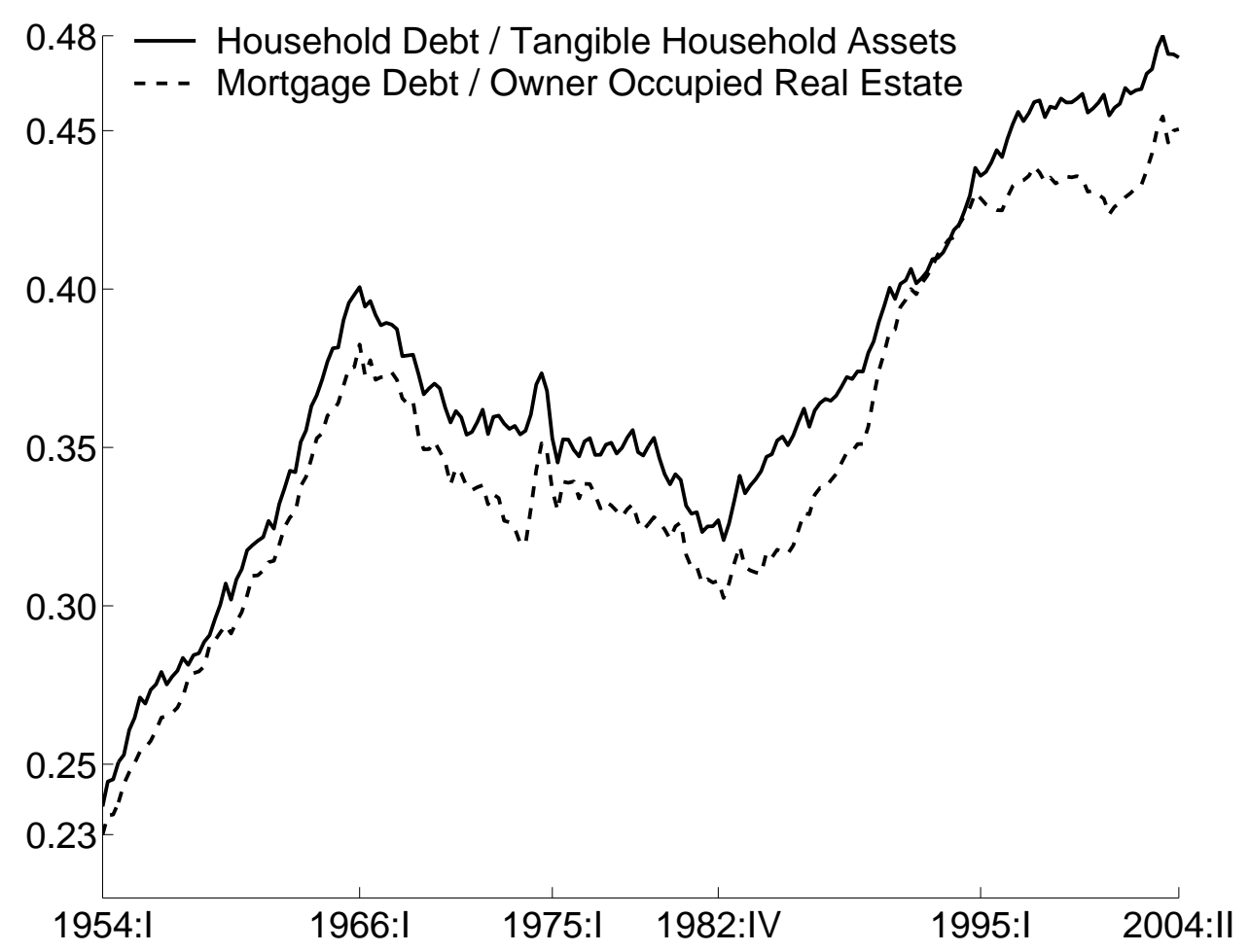

Figure 1: Ratios of Households' Debts to their Tangible Assets 


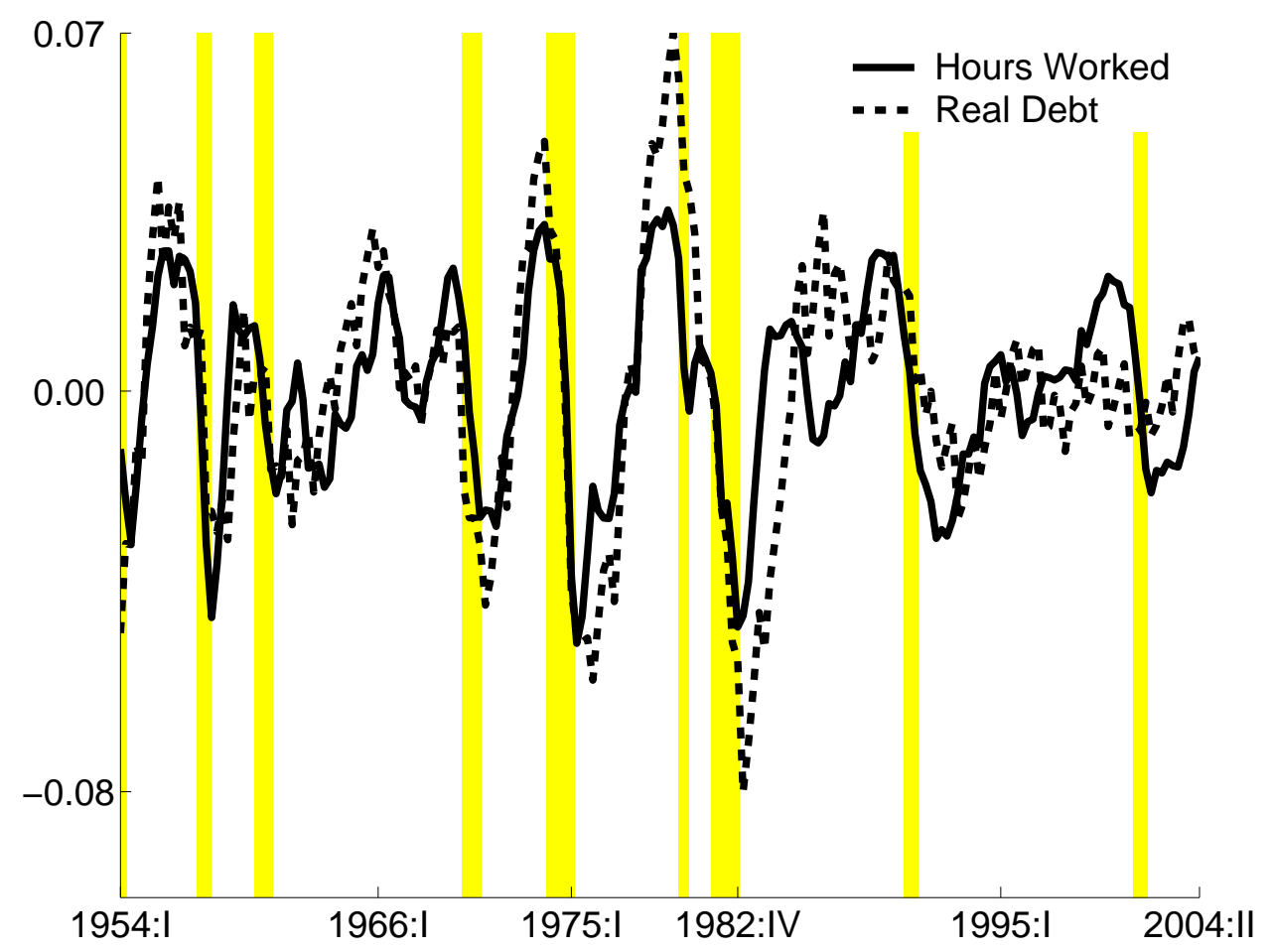

Figure 2: HP Filtered Real Household Debt and Hours Worked ${ }^{(i)}$

Note: (i) Debts and Assets measured at current market values. 

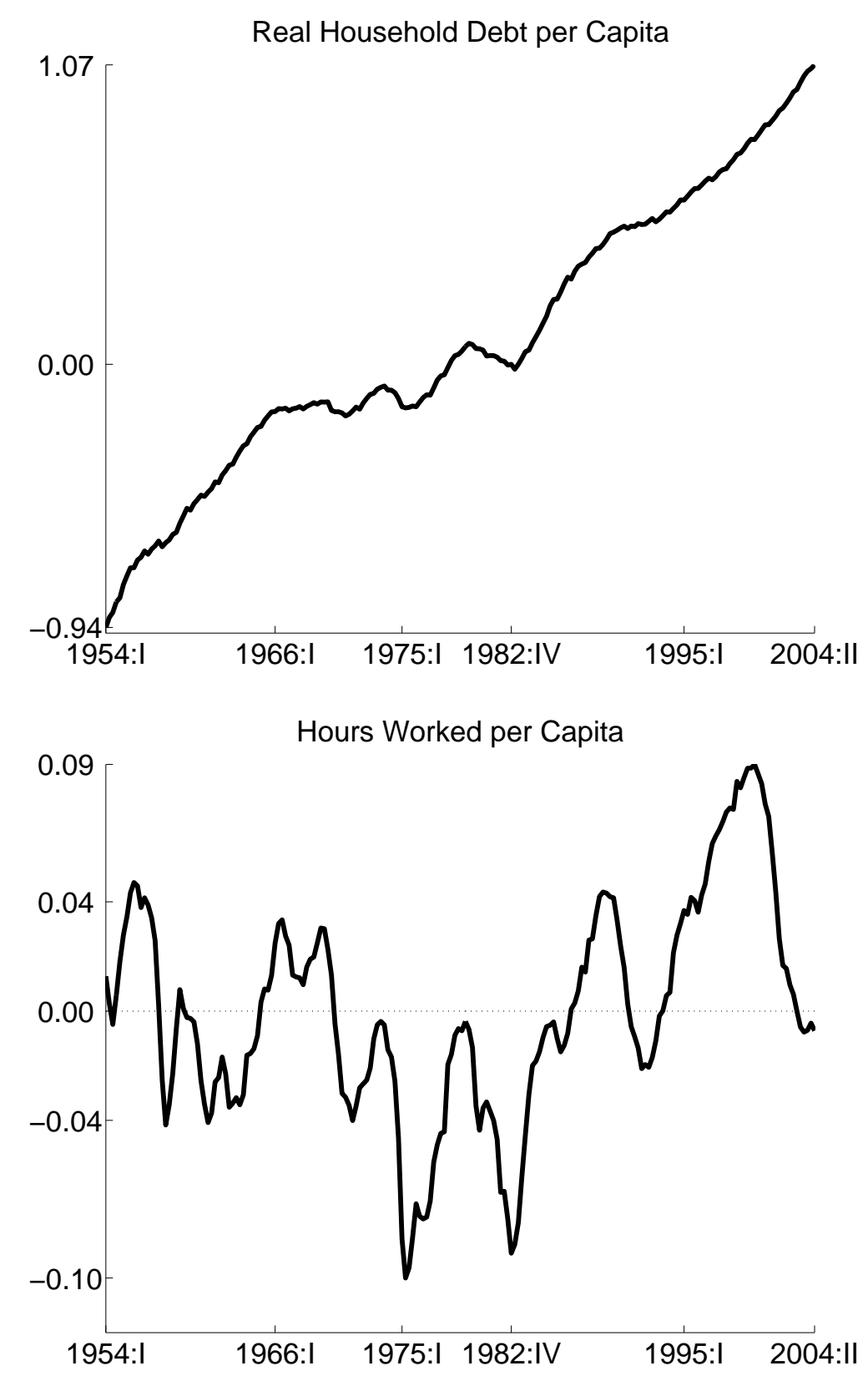

Figure 3: Real Household Debt and Hours Worked

Notes: The panels plot the logarithms of per capita hours worked and nominal household debt divided by the deflator for GDP. The average value of hours worked and the value in 1982 of real debt are normalized to zero. See the text for further details. 
Hours Worked

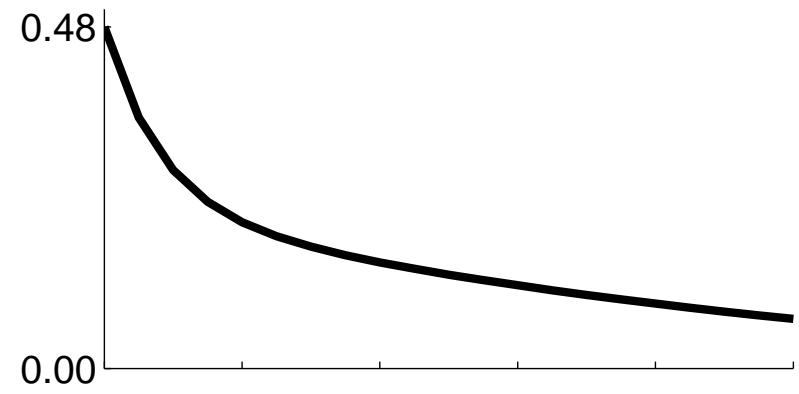

Borrower's Durable Consumption

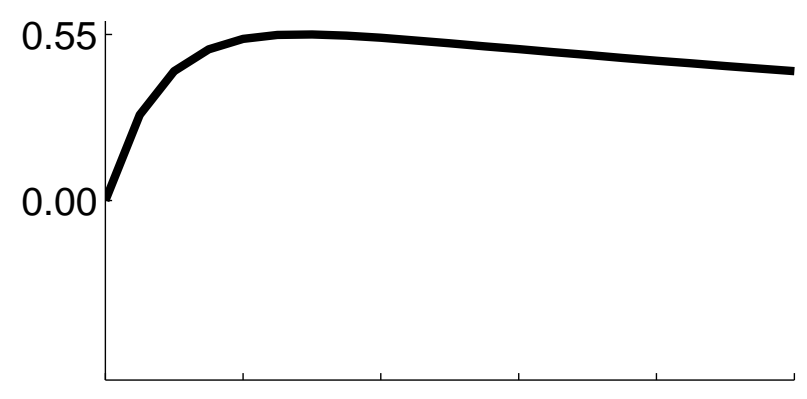

Borrower's Nondurable Consumption

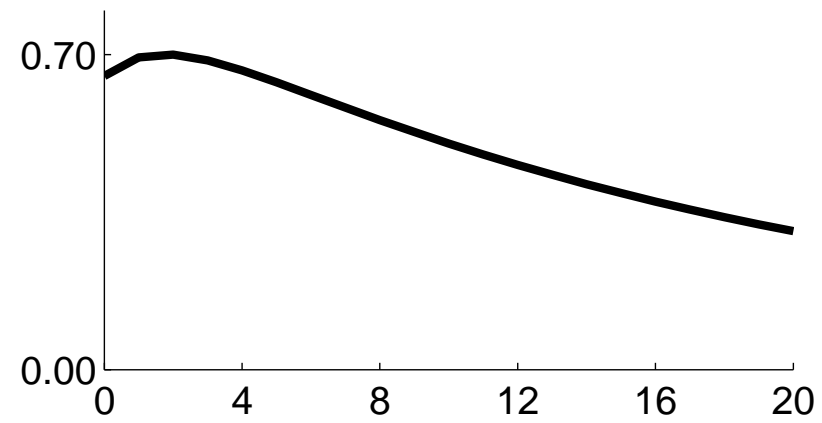

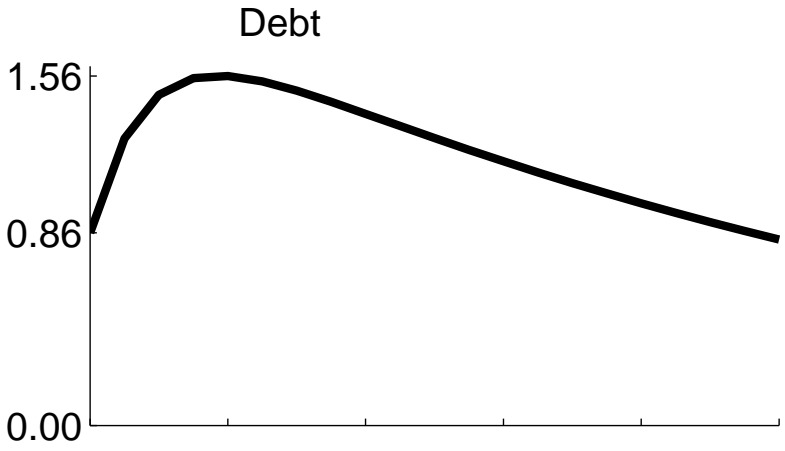

Saver's Durable Consumption

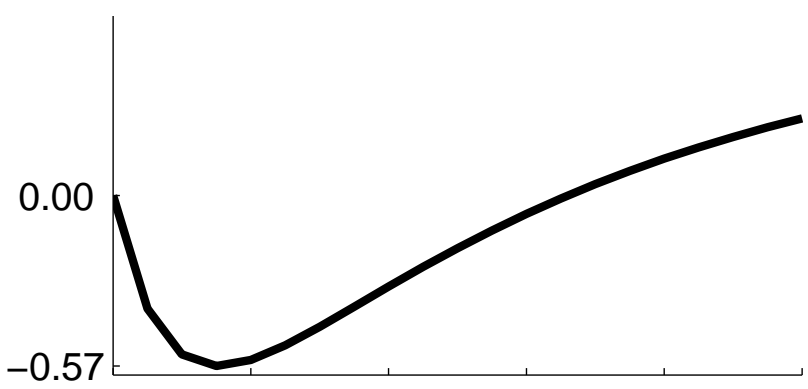

Saver's Nondurable Consumption

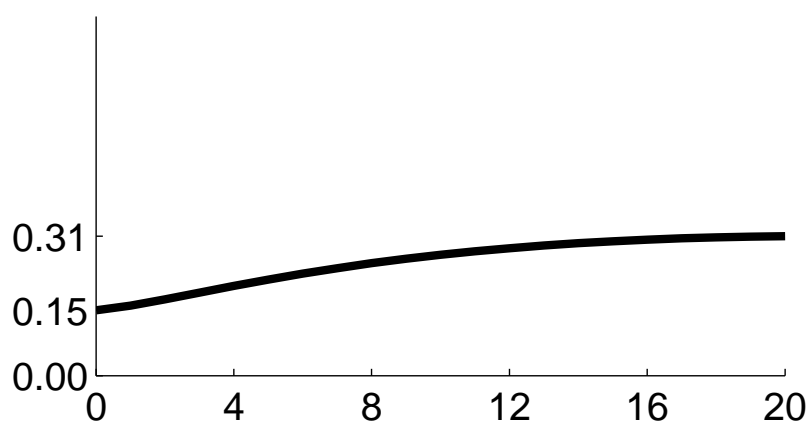

Figure 4: Household Responses with High Collateral Requirements to a Technology Shock 
Hours Worked

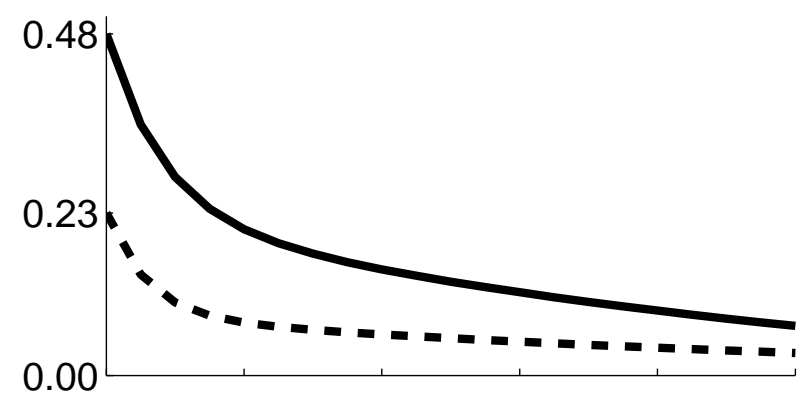

Nondurable Consumption
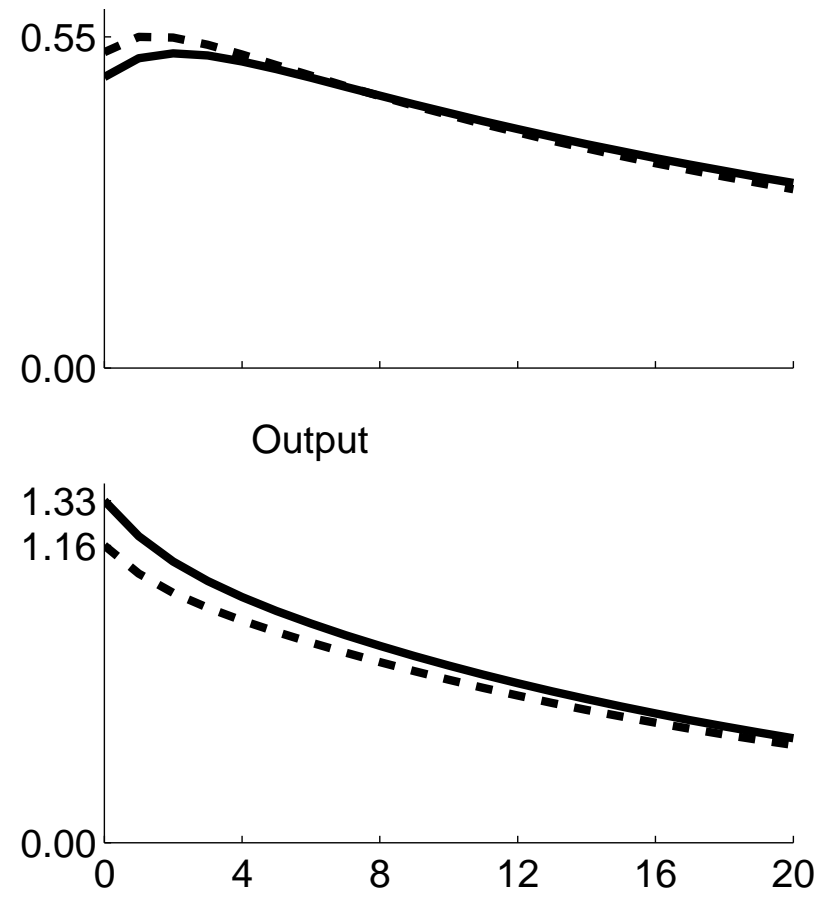

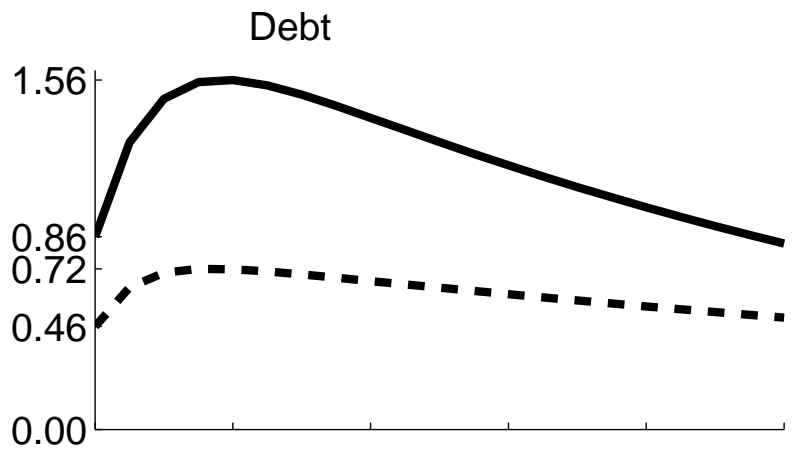

Durable Consumption Expenditures

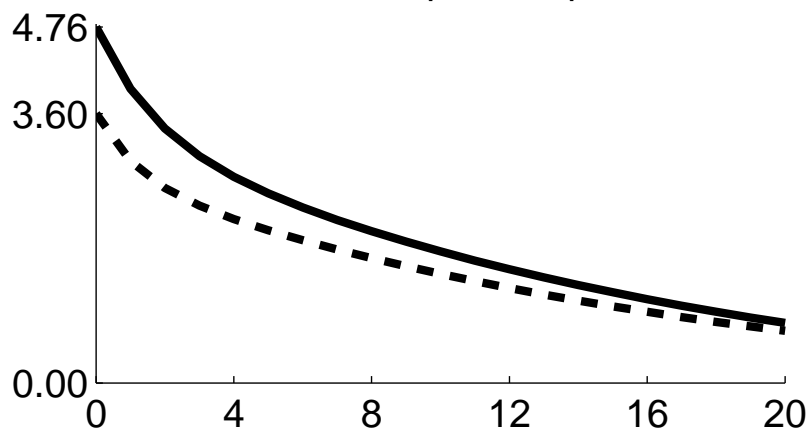

- High-Collateral Requirements - - Low-Collateral Requirements

Figure 5: Aggregate Responses to a Technology Shock 
Hours Worked

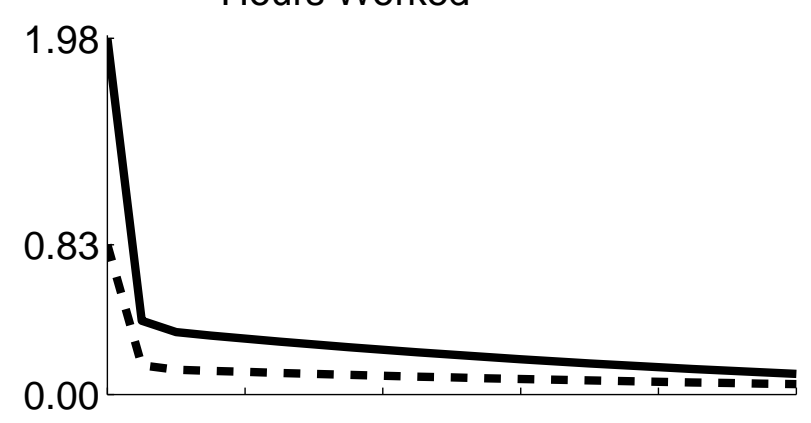

Nondurable Consumption

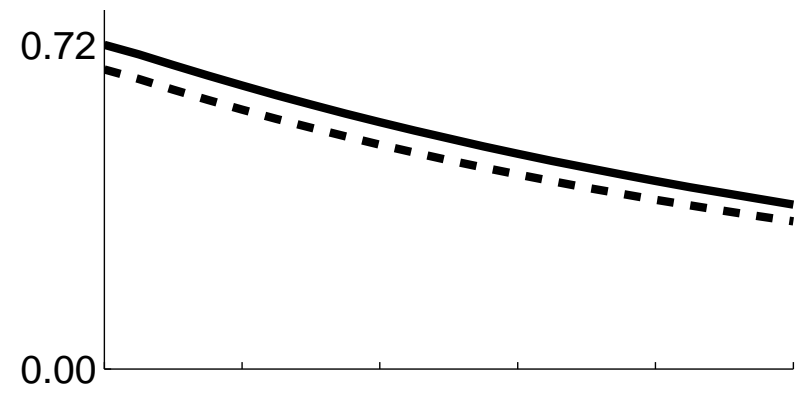

Output

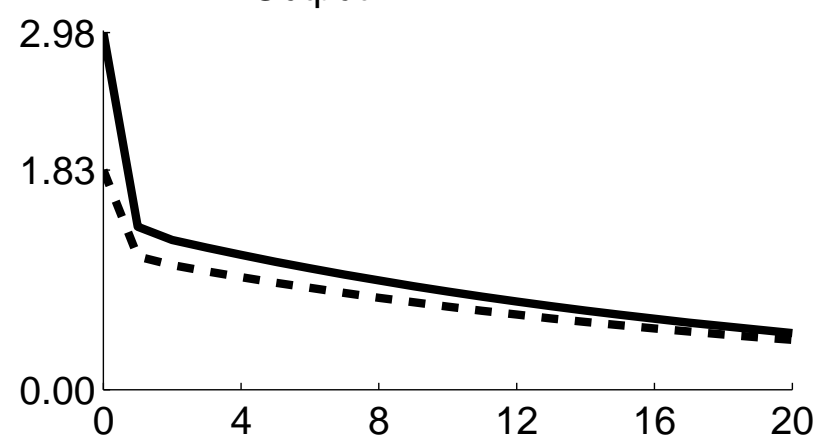

Debt

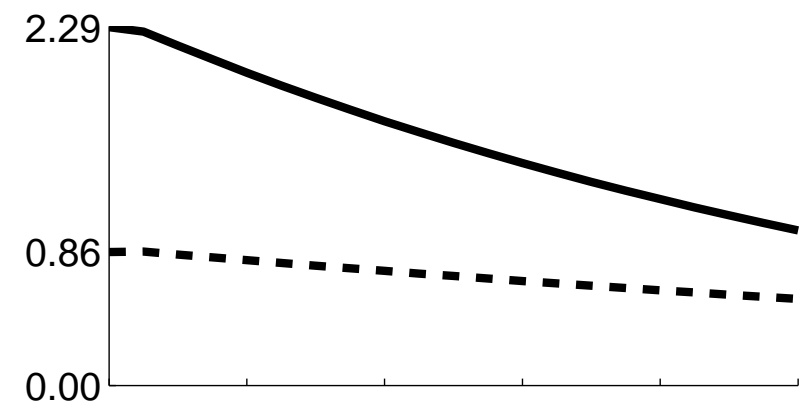

Durable Consumption Expenditures

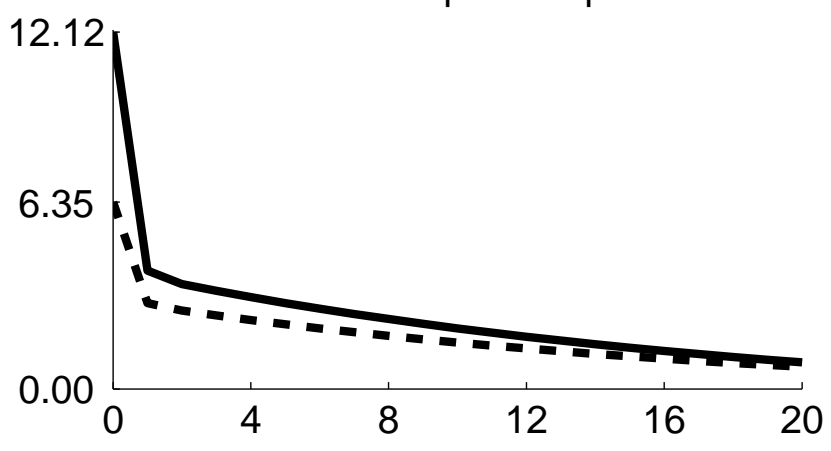

- High-Collateral Requirements

- - Low-Collateral Requirements

Figure 6: Aggregate Responses to a Technology Shock in the High-Substitution Economy 